\title{
Analysis on the Differences of Health Resources Allocation in Undeveloped Areas of Chongqing, China: A Cross-Sectional Study
}

\author{
Jian Zhang1, Jinlong Cai', Zhongchen $\mathrm{He}^{2}$, Chuan Pu${ }^{1}$, Guizhong Tang ${ }^{*}$ \\ ${ }^{1}$ School of Public Health and Management, Chongqing Medical University, Chongqing Research Center for Medical and Social \\ Development, Chongqing, China \\ ${ }^{2}$ Chongqing Sanitary Comprehensive Administrative Law Enforcement Corps, Chongqing, China \\ Email: *tangguizhong0325@163.com,zj199735@163.com
}

How to cite this paper: Zhang, J., Cai, J. L., He, Z. C., Pu, C., \& Tang, G. Z. (2020). Analysis on the Differences of Health Resources Allocation in Undeveloped Areas of Chongqing, China: A Cross-Sectional Study. Journal of Service Science and Management, $13,244-260$

https://doi.org/10.4236/jssm.2020.132016

Received: February 7, 2020

Accepted: April 11, 2020

Published: April 14, 2020

Copyright $\odot 2020$ by author(s) and Scientific Research Publishing Inc. This work is licensed under the Creative Commons Attribution International License (CC BY 4.0).

http://creativecommons.org/licenses/by/4.0/

\begin{abstract}
Objective: To analyze the status and differences of health resources allocation in undeveloped areas of Chongqing, China, and to provide empirical evidence for health planning and further optimization of health resources allocation. Methods: The comprehensive evaluation system for health resources allocation in underdeveloped areas was constructed. Afterwards, the entropy weight TOPSIS method was used to comprehensively evaluate the level of health resources allocation in 22 underdeveloped areas of Chongqing, and the $\mathrm{K}$-means cluster analysis method was used to classify the comprehensive evaluation results. Results: The level of health resources allocation in Chongqing's underdeveloped areas was relatively low and the regional differences were significant. The level of health resources allocation in 22 underdeveloped areas can be divided into 4 categories, of which Shizhu, Nanchuan, Qianjiang, and Liangping were better, Wuxi, Hechuan, Tongnan, and Youyang were poorer. Conclusion: It is recommended to increase the differentiation and pertinence of health policies in undeveloped areas, to achieve dynamic management and control of health resources, to promote the sustainable development of human resources for health, and to ensure that the level of health financing is improved.
\end{abstract}

\section{Keywords}

Underdeveloped Area, Health Resources Allocation, Entropy Weight Method, TOPSIS Method, Entropy Weight TOPSIS Method, Cluster Analysis

\section{Introduction}

The rational allocation of health resources is an important part of national 
health services, and its significance has become increasingly prominent with the development of China's economy and society (Gong \& Hu, 2005). The problem of unequal allocation of health resources in the undeveloped areas of western China is prominent (Zhang et al., 2018; Xu et al., 2014). Most of China's underdeveloped areas are concentrated in the northeast, central and western regions, and a few areas in developed areas. The land area accounts for $82.2 \%$ of the country, and the population accounts for $54.8 \%$ of the country (Shi \& Tang, 2015). In these regions, economic development is slow, per capita income is small, public investment is insufficient, and health services are inadequate. Therefore, it is of great significance to solve the problem of the allocation of health resources in undeveloped areas.

Since the implementation of the new health care reform in 2009 and the targeted poverty alleviation strategy in 2015, China has significantly optimized the allocation of health resources in undeveloped areas in the west. The capacity, accessibility, and resource utilization efficiency of medical services have improved significantly (Ding et al., 2018). However, previous studies confirmed that the fairness of the allocation of health resources in Inner Mongolia, Qinghai, Xinjiang, and Tibet by geographic area in western China was poor. Meanwhile, from the comparative analysis of the concentration of health resources and population, the accessibility of nursing staff in Gansu has declined (Shen et al., 2019), and there is still a large gap in the allocation of health resources between urban and rural areas (Wang et al., 2015).

Currently, the researches on the equalization of regional health resources allocation mostly focus on the current situation description, fairness analysis, and planning evaluation (Ouyang \& Zhang, 2016). Its measurement methods include range method, Theil index method, Gini coefficient method, and discrete index method. In recent years, scholars have begun to shift their attention to the issue of unequal health resources in the province, and use the data at the city or district level to explore the equalization of health resources and services in the province (Tao et al., 2014; Konings et al., 2010).

The entropy weight TOPSIS method, as one of the commonly used research methods, has been widely used to carry out the evaluation of health policy and service in various countries and regions (Ma et al., 2019; Hosseini et al., 2019), which has no strict restrictions on data distribution and sample size, and can effectively evaluate and rank research objects on the basis of making full use of the original data. However, it cannot explain the differences between the evaluation results, and it is impossible to conduct a classification study on the results. Cluster analysis is a multivariate statistical method for studying classification problems. Its principle is to determine the degree of intimacy between research objects and make appropriate classifications by analyzing the characteristics of the collected sample data (Dunn et al., 2018).

Located in the southwest of China's inland, Chongqing is the largest municipality in China and the only municipality in the western region. Its total area is 82,400 square kilometers, and it has 38 districts or autonomous counties ( $\mathrm{Li}$, 
2016). The resident population in 2019 was 31.2432 million and the GDP was 2,360,577 million yuan (Chongqing Statistic, 2019). In addition, Chongqing is located in the eastern of the Sichuan Basin. The landform is dominated by hills and mountains, of which $76 \%$ are mountains, so it is known as Mountain City. Specifically, the northeastern Chongqing is located in the Three Gorges Reservoir area and Qinba Mountain. It is an underdeveloped area in Chongqing that integrates large reservoirs, large mountains, and large rural areas. Coincidentally, the southeastern Chongqing is located in the extremely difficult and contiguous area of Wuling Mountain and is a gathering area for ethnic minorities. It is not difficult to understand that the economic development gap between regions in Chongqing's jurisdiction has further widened. Therefore, Chongqing has comprehensively reflected a series of characteristics of poverty alleviation and development in the western China, such as high mountains, high and cold, continuous extreme poverty, ethnic regions, etc., and its research has some typical exemplary significance.

Based on the above, this study combined entropy weight TOPSIS method and cluster analysis method to comprehensively evaluate the level and differences of health resources allocation in Chongqing's undeveloped areas. While exploring the operability and applicability of the above research methods, it will provide empirical basis for formulating health plans in the areas and further optimizing the allocation of health resources.

\section{Methods}

The research method includes three processes of evaluation index construction, entropy weight method analysis and TOPSIS method comprehensive evaluation, See Figure 1.

\subsection{Data Sources}

The definition of "underdeveloped area" in this study was based on China's GDP per capita $(64,644$ yuan) in 2018 , and areas below this standard were classified as underdeveloped areas, otherwise they were classified as developed areas (Zhang et al., 2019; Gao et al., 2018). With reference to the above criteria, a total of 23 districts in Chongqing were classified as underdeveloped areas in 2018. Among them, although the per capita GDP of the Dadukou was 63,902 yuan, it was not included in this study because it belongs to the core area of urban functions. The

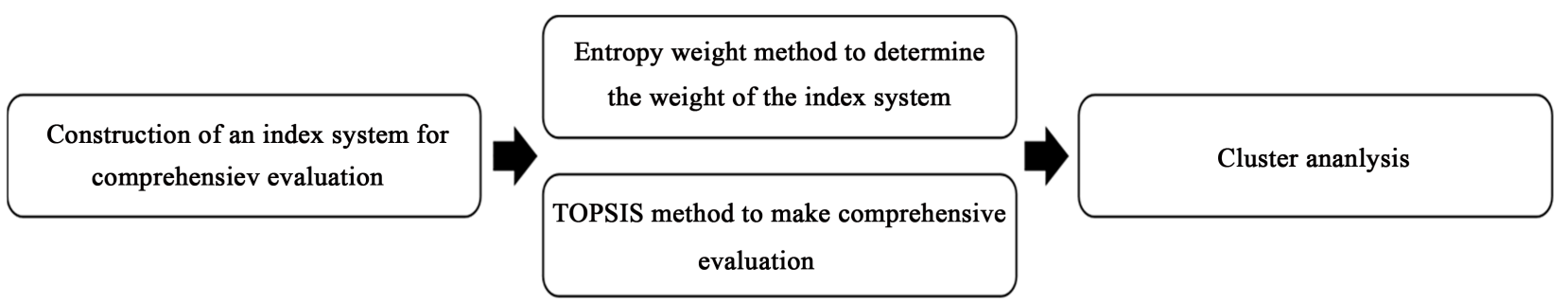

Figure 1. Research method. 
number of medical and health institutions, the number of health technicians, and the total assets of the medical and health institutions were derived from the Chongqing Health and Health Statistical Yearbook 2019. The relevant indicators of the basic population and economic conditions were derived from the Chongqing Statistical Yearbook 2019. The figures were as of the end of 2018.

\subsection{The Construction of the Evaluation Index System}

The construction of the evaluation index system is the primary link and core content of measuring the level of health resources allocation, and it is also a basic tool for quantitative analysis. This research followed the design principles of a standardized index system for health resources allocation, and took the research purpose, the operability, representativeness, and authority of the index as the principles (Gupta, 2018). In order to prevent the omission of key indicators, this study used a combination of theoretical analysis, document statistics, and brainstorming to theoretically select measurement indicators. Since the total index was directly related to the total number of units and the overall range, so structural index, proportional index, intensity index and average index were selected as the basic form of measurement index (Peng et al., 2019).

The final evaluation index system included three primary indicators and twelve secondary indicators as shown in Table 1 . It was consistent with the World Health Organization's definition of health resources and covers three aspects: funding, material and human resources. It should be pointed out that, because it was difficult to collect data on health expenditures, this study mainly evaluated them in terms of assets and liabilities, total income and composition of medical institutions in underdeveloped areas (Pang et al., 2015). Those secondary indicators included the average total assets of medical institutions ( $\mathrm{C} 1)$, the asset-liability ratio (C2), the average total income (C3), and the proportion of fiscal subsidy income (C4). At the same time, the reliability and validity of the index system were tested, and the results showed that show that Cronbach's $\alpha$ and CVI respectively were 0.831 and 0.796 .

\subsection{The Process of Calculation and Analysis}

Step 1: Construct the index evaluation matrix $X_{i j}$. The evaluation object of this study was 12 indicators of 22 underdeveloped areas in Chongqing. Therefore, an index evaluation matrix of $n=22$ and $m=12$ were constructed.

$X_{i j}(i=1,2,3, \cdots, n ; j=1,2,3, \cdots, m)$ represents the $j$-th data of the $i$-th area.

Step 2: Construct the standardized matrix $Y_{i j}$. The dimensionless processing was performed on the original matrix to construct $Y_{i j}$. The 12 indicators were all judged to be high-quality indicators, and no co-trend conversion was required. The minimum-maximum normalization method was used to normalize the original matrix.

$$
Y_{i j}=\frac{X_{i j}-X_{i j \min }}{X_{i j \max }-X_{i j \min }}
$$


Table 1. Evaluation index system for health resources allocation in undeveloped areas.

\begin{tabular}{|c|c|c|c|c|}
\hline \multirow{2}{*}{$\begin{array}{l}\text { Primary } \\
\text { indicators }\end{array}$} & \multicolumn{3}{|l|}{ Secondary indicators } & \multirow{2}{*}{$\begin{array}{l}\text { Inter-group } \\
\text { weights }\end{array}$} \\
\hline & Content & Code & $\begin{array}{l}\text { Intra-group } \\
\text { weights }\end{array}$ & \\
\hline \multirow{4}{*}{$\begin{array}{l}\text { Institutions } \\
\text { and Facilities }\end{array}$} & $\begin{array}{l}\text { Number of medical and health } \\
\text { institutions per } 1000 \text { resident population }\end{array}$ & A1 & 0.3024 & 0.1058 \\
\hline & $\begin{array}{l}\text { Number of primary health institutions } \\
\text { per } 1000 \text { resident population }\end{array}$ & $\mathrm{A} 2$ & 0.2841 & 0.0994 \\
\hline & $\begin{array}{l}\text { Number of beds in medical and health } \\
\text { institutions per } 1000 \text { resident population }\end{array}$ & $\mathrm{A} 3$ & 0.1519 & 0.0532 \\
\hline & $\begin{array}{l}\text { Number of equipment stations over } \\
¥ 10,000 \text { per } 1000 \text { resident population }\end{array}$ & $\mathrm{A} 4$ & 0.2615 & 0.0915 \\
\hline \multirow{4}{*}{$\begin{array}{c}\text { Health } \\
\text { Human } \\
\text { Resources }\end{array}$} & $\begin{array}{l}\text { Number of health technicians per } \\
1000 \text { resident population }\end{array}$ & B1 & 0.2882 & 0.1029 \\
\hline & $\begin{array}{l}\text { Number of practising(assistant) } \\
\text { physicians per } 1000 \text { resident population }\end{array}$ & B2 & 0.1641 & 0.0586 \\
\hline & $\begin{array}{l}\text { Number of general practitioners per } \\
10,000 \text { resident population }\end{array}$ & B3 & 0.3208 & 0.1146 \\
\hline & $\begin{array}{l}\text { Number of registered nurses per } \\
1000 \text { resident population }\end{array}$ & B4 & 0.2269 & 0.0810 \\
\hline \multirow{4}{*}{$\begin{array}{l}\text { Health } \\
\text { Financing }\end{array}$} & $\begin{array}{l}\text { Average total assets of medical } \\
\text { and health institutions }\end{array}$ & $\mathrm{C} 1$ & 0.3192 & 0.0935 \\
\hline & $\begin{array}{l}\text { Ratio of assets to liabilities of } \\
\text { medical and health institutions }\end{array}$ & $\mathrm{C} 2$ & 0.1676 & 0.0491 \\
\hline & $\begin{array}{l}\text { Average total income of medical } \\
\text { and health institutions }\end{array}$ & $\mathrm{C} 3$ & 0.3592 & 0.1052 \\
\hline & $\begin{array}{l}\text { The proportion of financial subsidy } \\
\text { income of medical and health institutions }\end{array}$ & $\mathrm{C} 4$ & 0.1539 & 0.0451 \\
\hline
\end{tabular}

Step 3: Calculate the entropy value $E_{j}$ and weight $W_{j}$ of the index (including intra-group weight and inter-group weight). If the information entropy of an indicator is smaller, it indicates that the degree of variation of the indicator value is greater, the larger the amount of information provided, the greater the role in the comprehensive evaluation, and the greater its weight.

$$
\begin{gathered}
E_{j}=-\ln (n)^{-1} \sum_{i=1}^{n} P_{i j} \ln P_{i j} \\
\left.P_{i j}=\frac{Y_{i j}}{\sum_{i=1}^{n} Y_{i j}} \text { (If } P_{i j}=0, \ln P_{i j}=0\right) \\
W_{j}=\frac{1-E_{j}}{m-\sum_{i=1}^{n} E_{j}}
\end{gathered}
$$

$\left(0 \leq W_{j} \leq 1\right.$, the sum of entropy weights of all indicators is 1$)$.

Step 4: Construct the weighted matrix $Z=\left(z_{i j}\right)_{n \times m}=\left(W_{j} Y_{i j}\right)_{n \times m}$, based on the 
standardized matrix $Y_{i j}$ and the weights of each index $W_{j}$.

Step 5: Calculate the euclidean distances $D_{i}^{+}$and $D_{i}^{-}$of each evaluation object from the positive ideal solution $Z_{j}^{+}$and the negative ideal solution $Z_{j}^{-}$.

$$
\begin{aligned}
& D_{i}^{+}=\sqrt{\sum_{j=1}^{m}\left(z_{i j}-z_{j}^{+}\right)^{2}}, z_{j}^{+}=\max \left\{z_{1 j}, z_{2 j}, \cdots, z_{n j}\right\} \\
& D_{i}^{-}=\sqrt{\sum_{j=1}^{m}\left(z_{i j}-z_{j}^{-}\right)^{2}}, z_{j}^{-}=\min \left\{z_{1 j}, z_{2 j}, \cdots, z_{n j}\right\}
\end{aligned}
$$

Step 6: Calculate the relative proximity of the evaluation object to the optimal value $\left(C_{i}\right)$. The closer $C_{i}$ is to 1 , the closer the evaluation object is to the positive ideal solution, the higher the level of health resources allocation in the area. In contrast, the closer to 0 , the lower the level of health resources allocation in the area.

$$
C_{i}=\frac{D_{i}^{-}}{D_{i}^{+}+D_{i}^{-}}
$$

Step 7: Cluster analysis. The K-means clustering analysis was performed on the comprehensive evaluation $C_{i}$ of health resources allocation in 22 regions.

\section{Results}

\subsection{Basic Situation}

The basic situation of health resources allocation in Chongqing's underdeveloped areas was shown in Table 2. In terms of institutions and facilities, there were 15 and 10 underdeveloped areas respectively with the number of medical and health institutions per thousand peoples (A1), and the number of beds in medical and health institutions per thousand peoples (A3) reached the Chongqing's average levels $(0.66,7.10)$. However, in terms of health human resources, 21 and 15 of the number of health technicians per thousand peoples (B1) and the number of general practitioners per thousand peoples (B3) were lower than the city's average levels $(6.75,1.97)$. Similarly, in terms of health funding, 18 and 21 of the average total assets of medical and health institutions $(\mathrm{C} 1)$ and the average total income $(\mathrm{C} 3)$ were lower than the city's average levels $(0.55,0.44)$. It was proved that the level of health funding security and health human resources allocation in Chongqing's underdeveloped areas was low.

In addition, the imbalance in the allocation of health resources between Chongqing's regions was also confirmed. For example, the number of beds in medical and health institutions per thousand peoples (A3) in Shizhu was as high as 9.72, which was in the forefront of underdeveloped areas, while Wuxi was only 4.42. For another example, Qianjiang had 7.65 health technicians per thousand peoples (B1), but Tongnan only 4.30 .

\subsection{The Results of Indicators Weighting}

After normalizing the original data, the intra-group weights and inter-group 
Table 2. Allocation of health resources in undeveloped areas of Chongqing in 2018.

\begin{tabular}{|c|c|c|c|c|c|c|c|c|c|c|c|c|c|c|}
\hline \multirow{2}{*}{ Areas } & \multirow{2}{*}{$\begin{array}{l}\text { GDP } \\
\text { per } \\
\text { capita }\end{array}$} & \multirow{2}{*}{$\begin{array}{c}\text { Permanent } \\
\text { Residents } \\
\text { (1000 persons) }\end{array}$} & \multicolumn{4}{|c|}{ Institutions and Facilities } & \multicolumn{4}{|c|}{ Health Human Resources } & \multicolumn{4}{|c|}{ Health Financing } \\
\hline & & & A1 & $\mathrm{A} 2$ & A3 & A4 & B1 & B2 & B3 & B4 & $\mathrm{C} 1$ & $\mathrm{C} 2$ & $\mathrm{C} 3$ & $\mathrm{C} 4$ \\
\hline Citywide & 65933 & 31017.9 & 0.66 & 0.63 & 7.10 & 5.38 & 6.75 & 2.46 & 1.97 & 3.07 & 0.55 & 0.41 & 0.44 & 0.14 \\
\hline Tongliang & 62945 & 726.0 & 1.11 & 1.09 & 5.73 & 4.87 & 5.74 & 2.26 & 2.92 & 2.44 & 0.28 & 0.62 & 0.21 & 0.17 \\
\hline Wanzhou & 59640 & 1647.5 & 0.77 & 0.74 & 6.35 & 5.61 & 6.69 & 2.56 & 2.14 & 3.00 & 0.38 & 0.44 & 0.40 & 0.08 \\
\hline Tongnan & 52866 & 720.6 & 0.57 & 0.55 & 5.36 & 1.72 & 4.30 & 1.51 & 1.35 & 1.73 & 0.38 & 0.52 & 0.30 & 0.21 \\
\hline Wulong\# & 52163 & 348.2 & 0.98 & 0.94 & 7.16 & 3.43 & 4.43 & 1.87 & 1.84 & 1.52 & 0.24 & 0.27 & 0.18 & 0.20 \\
\hline Qianjiang $^{\#}$ & 51104 & 483.9 & 0.61 & 0.58 & 8.33 & 6.09 & 7.65 & 2.17 & 2.23 & 3.72 & 0.60 & 0.53 & 0.47 & 0.14 \\
\hline Hechuan & 50663 & 1407.2 & 0.65 & 0.63 & 4.84 & 3.18 & 5.13 & 1.94 & 1.12 & 2.40 & 0.32 & 0.51 & 0.26 & 0.21 \\
\hline Liangping & 50643 & 654.1 & 0.92 & 0.91 & 6.12 & 9.64 & 5.39 & 2.03 & 2.78 & 2.26 & 0.33 & 0.58 & 0.20 & 0.20 \\
\hline Qijiang & 50521 & 1099.8 & 0.54 & 0.51 & 7.83 & 4.90 & 6.19 & 1.95 & 1.45 & 2.98 & 0.47 & 0.51 & 0.38 & 0.10 \\
\hline Nanchuan & 47432 & 591.1 & 0.70 & 0.66 & 7.13 & 7.31 & 6.29 & 2.17 & 2.30 & 3.09 & 0.64 & 0.59 & 0.33 & 0.14 \\
\hline Shizhu $^{\#}$ & 46552 & 378.0 & 0.70 & 0.67 & 9.72 & 5.92 & 6.58 & 2.42 & 3.28 & 3.07 & 0.62 & 0.43 & 0.40 & 0.18 \\
\hline Dianjiang & 45162 & 701.8 & 0.61 & 0.59 & 7.29 & 5.07 & 6.08 & 2.12 & 0.88 & 2.56 & 0.61 & 0.52 & 0.43 & 0.16 \\
\hline Zhongxian & 41682 & 738.8 & 1.06 & 1.04 & 6.10 & 2.97 & 4.89 & 1.86 & 1.72 & 1.99 & 0.24 & 0.37 & 0.17 & 0.20 \\
\hline Fengjie $^{\#}$ & 41004 & 733.3 & 0.70 & 0.68 & 7.33 & 3.52 & 5.52 & 1.86 & 3.15 & 2.49 & 0.37 & 0.45 & 0.28 & 0.17 \\
\hline Fengdu ${ }^{\#}$ & 40150 & 585.2 & 0.79 & 0.76 & 7.79 & 3.52 & 5.25 & 1.73 & 1.74 & 2.29 & 0.34 & 0.53 & 0.24 & 0.17 \\
\hline Kaizhou" & 40058 & 1181.1 & 0.60 & 0.58 & 6.57 & 3.85 & 4.69 & 1.94 & 1.35 & 2.01 & 0.39 & 0.25 & 0.34 & 0.16 \\
\hline Xiushan $^{\#}$ & 38221 & 485.7 & 0.70 & 0.67 & 6.35 & 3.71 & 6.03 & 2.10 & 0.86 & 2.63 & 0.38 & 0.56 & 0.29 & 0.25 \\
\hline Pengshui ${ }^{\# \star ~}$ & 34822 & 488.5 & 0.86 & 0.83 & 7.24 & 5.34 & 5.14 & 1.83 & 1.92 & 2.12 & 0.33 & 0.43 & 0.21 & 0.17 \\
\hline Wushan" & 31925 & 446.8 & 0.85 & 0.83 & 7.37 & 2.06 & 5.38 & 1.87 & 1.54 & 2.15 & 0.28 & 0.65 & 0.24 & 0.22 \\
\hline Chengkou $^{\# *}$ & 30249 & 184.4 & 1.01 & 0.97 & 6.38 & 3.99 & 5.86 & 1.98 & 2.28 & 2.13 & 0.20 & 0.38 & 0.21 & 0.25 \\
\hline Yunyang ${ }^{\#}$ & 29531 & 931.4 & 0.73 & 0.72 & 6.62 & 2.62 & 4.82 & 1.99 & 1.48 & 1.81 & 0.46 & 0.57 & 0.24 & 0.20 \\
\hline Youyang** & 28872 & 547.1 & 0.59 & 0.56 & 6.24 & 2.90 & 4.37 & 1.56 & 0.95 & 1.73 & 0.28 & 0.38 & 0.26 & 0.19 \\
\hline Wuxi ${ }^{\# *}$ & 27069 & 383.2 & 0.94 & 0.91 & 4.42 & 2.52 & 4.56 & 1.73 & 0.99 & 1.45 & 0.25 & 0.47 & 0.18 & 0.30 \\
\hline
\end{tabular}

\#. the National Key Poverty Alleviation and Development Country announced (referred to as "poverty counties") by the General Office of the State Council of PRC. in 2012. *. as of December 2019, 4 poverty counties in Chingqing still below national standards for defining poverty counties.

weights for each indicator were calculated (Table 1). In terms of institutions and facilities, the number of medical and health institutions per 1000 resident population (0.3024) had a larger weight, and the number of beds in medical and health institutions per 1000 resident population (0.1519) has a smaller weight, with a range of 0.1505 . In terms of health human resources, the number of general practitioners per 10,000 resident population (0.3208) had a greater weight, and the number of practicing (assistant) doctors per 1000 resident population (0.1641) had a smaller weight, with a range of 0.1567. In terms of health financing, the average total assets (0.3192) and average total income (0.3592) of medical institutions had a greater weight, and the total of the two exceeds $65 \%$, which was an important indicator affecting the comprehensive evaluation score and 
ranking of this dimension.

\subsection{The Results of Entropy Weight TOPSIS Method}

The entropy weight TOPSIS method was used to comprehensively evaluate the health resources allocation level of 22 undeveloped areas in Chongqing. See Table 3. Shizhu (0.6589), Nanchuan (0.6077), Qianjiang (0.6066) had higher levels of health resources allocation, and their relative closeness to the optimal value $\left(C_{i}\right)$ was over $60 \%$. In contrast, Wuxi (0.2669), Hechuan (0.2524), Tongnan (0.2401), and Youyang (0.1815) had lower levels, and their relative closeness to the optimal value $\left(C_{i}\right)$ was less than $30 \%$.

\subsection{The Results of Cluster Analysis}

K-means cluster analysis was performed on the $C_{i}$ of the comprehensive assessment of the overall health resources allocation in 22 undeveloped areas. See Table 4 and Figure 2. The analysis of variance (ANOVA) was performed on the clustering results. The variances of all groups were equal and $\mathrm{P}<0.001$, indicating that there was a statistical difference between the groups.

Table 3. Comprehensive evaluation of health resources allocation.

\begin{tabular}{|c|c|c|c|c|c|c|c|c|}
\hline \multirow[t]{2}{*}{ Areas } & \multicolumn{2}{|c|}{$\begin{array}{l}\text { Institutions } \\
\text { and Facilities }\end{array}$} & \multicolumn{2}{|c|}{$\begin{array}{c}\text { Health Human } \\
\text { Resources }\end{array}$} & \multicolumn{2}{|c|}{ Health Financing } & \multicolumn{2}{|c|}{ Overall } \\
\hline & $\mathrm{Ci}$ & Ranking & $\mathrm{Ci}$ & Ranking & $\mathrm{Ci}$ & Ranking & $\mathrm{Ci}$ & Ranking \\
\hline Shizhu & 0.4750 & 5 & 0.8424 & 1 & 0.7598 & 3 & 0.6589 & 1 \\
\hline Nanchuan & 0.5524 & 3 & 0.6188 & 6 & 0.6697 & 4 & 0.6077 & 2 \\
\hline Qianjiang & 0.4371 & 8 & 0.6728 & 4 & 0.7829 & 1 & 0.6066 & 3 \\
\hline Liangping & 0.7944 & 1 & 0.6194 & 5 & 0.3104 & 15 & 0.5916 & 4 \\
\hline Wanzhou & 0.4567 & 7 & 0.5906 & 7 & 0.5203 & 6 & 0.5186 & 5 \\
\hline Tongliang & 0.5577 & 2 & 0.6828 & 3 & 0.2800 & 18 & 0.5181 & 6 \\
\hline Fengjie & 0.2633 & 17 & 0.6964 & 2 & 0.3903 & 11 & 0.4666 & 7 \\
\hline Dianjing & 0.3503 & 11 & 0.2627 & 16 & 0.7780 & 2 & 0.4479 & 8 \\
\hline Qijiang & 0.3214 & 13 & 0.3877 & 9 & 0.5921 & 5 & 0.4216 & 9 \\
\hline Chengkou & 0.4611 & 6 & 0.5101 & 8 & 0.2345 & 20 & 0.4096 & 10 \\
\hline Pengshui & 0.4903 & 4 & 0.3859 & 10 & 0.2715 & 19 & 0.3964 & 11 \\
\hline Zhongxian & 0.4325 & 9 & 0.3124 & 12 & 0.1806 & 21 & 0.3404 & 12 \\
\hline Fengdu & 0.3195 & 14 & 0.3506 & 11 & 0.3337 & 14 & 0.3333 & 13 \\
\hline Xiushan & 0.2646 & 16 & 0.2651 & 15 & 0.4728 & 7 & 0.3274 & 14 \\
\hline Wulong & 0.4158 & 10 & 0.3104 & 13 & 0.1786 & 22 & 0.3251 & 15 \\
\hline Kaizhou & 0.2366 & 18 & 0.2093 & 19 & 0.4708 & 8 & 0.3085 & 16 \\
\hline Wushan & 0.2860 & 15 & 0.2939 & 14 & 0.3453 & 13 & 0.3060 & 17 \\
\hline Yunyang & 0.2239 & 19 & 0.2361 & 17 & 0.4514 & 9 & 0.3052 & 18 \\
\hline Wuxi & 0.3376 & 12 & 0.0625 & 21 & 0.2907 & 17 & 0.2669 & 19 \\
\hline Hechuan & 0.1832 & 20 & 0.2197 & 18 & 0.3564 & 12 & 0.2524 & 20 \\
\hline Tongnan & 0.0481 & 22 & 0.1665 & 20 & 0.4508 & 10 & 0.2401 & 21 \\
\hline Youyang & 0.1468 & 21 & 0.0611 & 22 & 0.2967 & 16 & 0.1815 & 22 \\
\hline
\end{tabular}




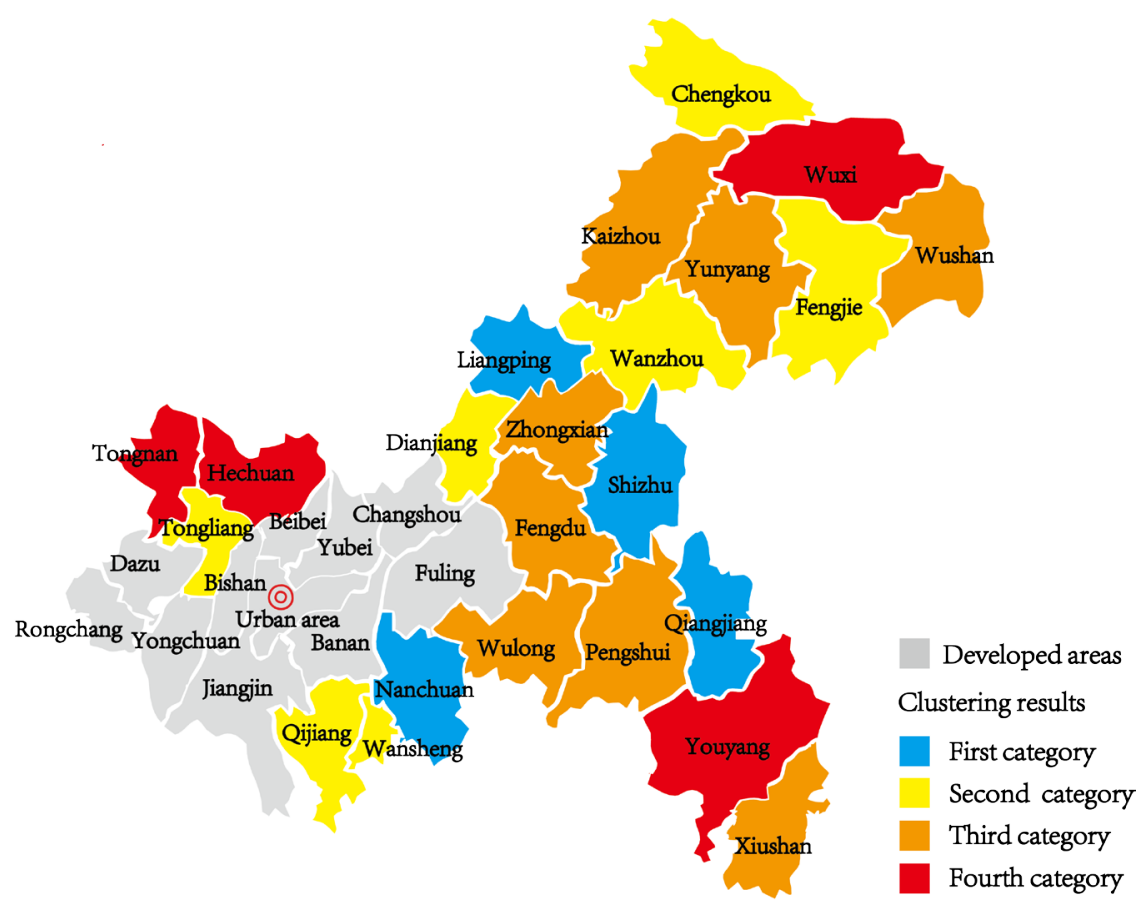

Figure 2. Cluster analysis map of health resources allocation in Chongqing's underdeveloped areas.

Table 4. The clustering results of health resources allocation.

\begin{tabular}{|c|c|c|c|c|}
\hline Clustering Results & $\begin{array}{l}\text { Number } \\
\text { of Areas }\end{array}$ & Regions & Mean of Ci & ANOVA \\
\hline First category & 4 & $\begin{array}{l}\text { Shizhu, Nanchuan, } \\
\text { Qianjiang, Liangping }\end{array}$ & 0.6162 & \\
\hline Second category & 6 & $\begin{array}{l}\text { Wanzhou, Tongliang, Fengjie, } \\
\text { Dianjiang, Qijiang, Chengkou }\end{array}$ & 0.4637 & $\mathrm{~F}=89.908$, \\
\hline Third category & 8 & $\begin{array}{c}\text { Pengshui, Zhongxian, Fengdu, } \\
\text { Xiushan, Wulong, Kaizhou, } \\
\text { Wushan, Yunyang }\end{array}$ & 0.3303 & $\mathrm{P}<0.001$ \\
\hline Fourth category & 4 & Wuxi, Hechuan, Tongnan, Youyang & 0.2352 & \\
\hline
\end{tabular}

The results showed that the level of health resources allocation in Chongqing's underdeveloped areas can be clustered into four categories. Among them, the first category of areas (including Shizhu, Nanchuan, Qianjiang and Liangping) had the best allocation of health resources, with an mean $C_{i}$ of 0.6162 . But the fourth category of areas (including Wuxi, Hechuan, Tongnan and Youyang) had the worst allocation, with an mean $C_{i}$ of 0.2352 . Noteworthy, the mean of $C_{i}$ in the comprehensive evaluation of the first category of areas was 2.47 times that of the first category, indicating that there was a significant difference in the allocation of health resources between various types of regions. With reference to the per capita GDP and resident population of each region in Table 1, it can be found that the fourth category are mainly poverty regions or the countries with a large population base, concentrated in the northeastern and southeastern 
mountains of Chongqing.

\section{Discussion and Suggestions}

\subsection{Further Research on the Fairness of Health Resources Allocation in Underdeveloped Areas}

Health resources are the material basis for people to maintain their own health. Its fairness determines whether individuals can be effectively protected in society (Bo et al., 2014). Through literature search, we found that there were currently few studies on the allocation of health resources in undeveloped areas around the world. According to this, the corresponding functional departments of the Chinese government should fully recognize the importance of fairness in medical services, and from the overall perspective of the construction of Healthy China, organize and support professional research teams to carry out the fairness of the allocation of health resources in undeveloped areas. At the same time, strengthen the government's responsibility and role in the fair allocation of health resources, coordinate economic development in different regions, and promote balanced development of health resources in each region.

\subsection{Strengthen the Differences and Pertinence of Regional Health Policies, and Optimize the Layout and Structure of Health Resources between Regions}

From the results of entropy weight TOPSIS and cluster analysis, it can be proved that the level of health resources allocation in Chongqing's underdeveloped areas is low and there are significant regional differences. The frist category's areas $\left(C_{i}\right.$ $=0.6162$ ) such as Shizhu and Nanchuan have better health resources allocation levels. The fourth category's areas $\left(C_{i}=0.2352\right)$ such as Wuxi and Hechuan have poor level.

The level of health resources allocation in the region is affected by multiple factors such as economy, policy, population distribution and geographical environment. In view of the differences in the allocation of health resources within the above-mentioned regions, governments of various countries should strengthen the differences and pertinence of health policy formulation, take full account of the regional differences, and then further propose health resource plans that better meet the needs ( $\mathrm{Li}$ et al., 2019). For the frist category' areas where health resources are relatively concentrated, it is vital to appropriately reduce investment, improve management capabilities, and focus on optimizing the resource structure to improve allocation efficiency. For the second category' areas with more abundant health resources, governments should maintain moderate development and meet the overall health resource planning under the premise, increase the input of factors reasonably according to the changes in demand (Sun \& Luo, 2017). In particular, for regions with weak resources in the third and fourth categories, it is of great that continue to increase policy preferences and financial investment, make up for the shortfall in supply, improve the network layout, and promote the availability and inclusiveness of medical services (Zhou 
\& Ni, 2017).

\subsection{Strictly Plan Increments, Scientifically Adjust Stocks, and Achieve Dynamic Management and Control of Health Resources}

There is a double dilemma of insufficient investment and underutilization of health resources allocation in undeveloped areas. For example, the comprehensive evaluation $C_{i}$ in the institutional and facility dimensions of Pengshui (0.6478) was 3.25 times higher than that in Shizhu (0.1994), suggesting that the configuration level of hardware facilities and population accessibility in Shizhu were significantly worse. For another example, although Chengkou had increased the number of beds and medical equipment above 10,000 yuan by 1.35 times and 2.06 times in 2015-2018, reaching 6.38 per thousand peoples and 3.99 per thousand peoples. The hospital bed utilization rate was only $75 \%$ in 2018 , and oversupply such as "medical equipment idle" is prominent (Feng et al., 2018).

Adjusting structural issues in the production, distribution, and use of health resource elements through supply-side reforms is the key path to coordinating the issue of "fairness and efficiency" in health resources allocation (Feng et al., 2017). Therefore, it is the responsibility of the government that calculate the target and distribution of health resources, with the principles of strictly planning increments and scientifically adjusting stocks, when conducting health planning for underdeveloped areas in accordance. Meanwhile, the government should also focus on increasing the effective supply, make up for the shortcomings, and adjust the internal proportion of health investment (Gardner et al., 2018). Furthermore, it is crucial to explore the establishment of a monitoring and evaluation mechanism, and to conduct macro dynamic control of the allocation of health resources in the region.

\subsection{Promote the Sustainable Development of Health Human Resources through Broadening the Introduction Channels and Optimizing the Incentive Mechanism}

Except Wanzhou and Qianjiang, the number of practicing (assistant) physicians and registered nurses per thousand resident population in other areas were lower than the targets set out in the Outline of the National Medical Service System Planning 2015-2020, issued by the General Office of the State Council of PRC., that is to reach 2.5 and 3.14 people per thousand people in 2020 (Chen et al., 2019). The problem of insufficient general practitioner (GPs) allocation is also worthy of attention, with only $36.4 \%$ of the area's GPs per 10,000 people meeting the 2020 target.

It is undeniable that under the guidance of China's new health care reform and health poverty alleviation policies, local governments have continuously increased their investment in health human resources, including the construction of GPs (Zhang et al., 2020). However, the health workforce is different from 
hardware facilities, and its improvement requires a longer-term process. The number and structure of health workforce resources between regions are limited in the short term $(\mathrm{Xu}, 2011)$. Based on this, on the one hand, the government should pay more attention to widening the channels for talent introduction on the basis of stabilizing the existing staff (Tursunbayeva et al, 2015). On the other hand, the breakthrough for medical institutions is to strengthen personnel incentive mechanisms in terms of optimizing employment management and performance evaluation (George et al, 2018). At the same time, relying on counterpart support, targeted training of general practitioners, telemedicine and other health personnel training models, jointly promote the development of underdeveloped areas.

\subsection{Steadily Improve Health Financing, Ensure Priority Investment in Medical and Health Undertakings}

The underdeveloped areas face great difficulties in raising health funds under a weak economic development system. Also taking Chengkou as an example, the average total assets and average total income of its medical and health institutions were only 20,400 yuan and 10,800 yuan, which were far lower than the Chongqing's average level. In addition, the amount of debt of medical institutions in undeveloped areas were lower than those in developed areas, but the overall debt ratio of their assets was higher than in developed areas. This phenomenon of high debt ratio under low debt reflected the more severe asset operation dilemma of institutions in undeveloped areas (Liang, 2003).

Accordingly, it is imperative for the government to attach great importance to the inequality of health financing in undeveloped areas. On the one hand, increase the central government's financial transfer payments to underdeveloped and poor areas, standardize the use of special appropriations and subsidies, and prioritize investment in medical and health services (Li et al., 2018). On the other hand, while encouraging social forces to invest in medical treatment, actively promote the new-type urbanization in undeveloped areas (Fang et al., 2015), urge local economic development and improve the efficiency of medical and health resources through population concentration (Wei et al., 2017).

\section{Limitations and Future Research}

We acknowledge that this study has several limitations that should be improved in future research. Firstly, we selected only 22 underdeveloped areas of Chongqing in western China as the research objects. Except for population and economy, the mediating role of geographical environment (such as transportation network, landform, natural disaster, communication), social culture (such as customs, religions, consumer, social class) and other potential influencing factors in health resources allocation had not been considered. Secondly, the elements of the evaluation index system in this study were not comprehensive. For example, previous research had shown that public health programs, as a core project of population health promotion, should be incorporated into regional 
health service planning and evaluation as essential indicators (Song et al., 2019; Glen \& Cezar, 2017). However, due to difficulties in collecting information and data, we did not include such indicators in this study. In future research, in addition to overcome such difficulties, we build a more scientific and systematic evaluation system for the allocation of health resources in underdeveloped areas based on Delphi method and analytic hierarchy process.

\section{Summary}

According to the results of the present study, the level of equalization of medical resource allocation in sparsely populated and poor areas is generally low, and there are significant differences in health resources allocation among regions in the undeveloped areas. Therefore, it is essential to strengthen government's responsibility and role in the fair allocation of health resources, coordinate the economic development of different areas, and promote the balanced development of health resources in each area. First of all, in areas where the relative demand for health resources is greater than the relative supply, more resources should be allocated to meet residents' demand for health resources. In contrast, in areas where the relative supply of health resources is greater than the relative demand, the redistribution of resources should be reduced accordingly to ensure the optimal allocation of health resources.

\section{Funding}

This study was supported by 2018 Technology Foresight and Institutional Innovation Project of Chongqing Science and Technology Bureau

(No.cstc2018jsyj-zdcxX0052).

\section{Conflicts of Interest}

The authors declare no conflicts of interest regarding the publication of this paper.

\section{References}

Bo, G., Wang, Y., Yang, W., Wang, L., Cui, Z., \& Xia, Q. (2014). Policy Choices or the Equity of Health Resources Allocation. Chinese Health Resource, 6, 477-481. (In Chinese)

Chen, F., Zhao, C., Yu, Q., Yin, W., Huang, D., Sun, K., Chen, Z., \& Guo, H. (2019). Analysis and Forecast of Human Resources Allocation of General Practitioners in China. Chinese Health Statistics, 36, 678-681. (In Chinese)

Chongqing Statistic (2019). Chongqing's Economic Operation in 2019. http://tji.cq.gov.cn/tjsj/sjid/202001/t20200120 462327.htm

Ding, J., Hu, X., Zhang X., Shang, L., Yu, M., \& Chen, H. (2018). Equity and Efficiency of Medical Service Systems at the Provincial Level of China's Mainland: A Comparative Study from 2009 to 2014. BMC Public Health, 18, 214.

https://doi.org/10.1186/s12889-018-5084-7

Dunn, H., Quinn, L., Corbridge, S. J., Eldeirawi, K., Kapella, M., \& Collins, E. G. (2018). 
Cluster Analysis in Nursing Research: An Introduction, Historical Perspective, and Future Directions. Western Journal of Nursing Research, 40, 1658-1676. https://doi.org/10.1177/0193945917707705

Fang, C., Ma H., \& Wang J. (2015). A Regional Categorization for "New-Type Urbanization" in China. PLoS ONE, 10, e0134253. https://doi.org/10.1371/journal.pone.0134253

Feng, K., Pu, X., Tang, G., Cheng, X., \& He, Z. (2018). Discussing the Path to Precise Poverty Alleviation of Primary Medical Care in Rural China. The Chinese Health Service Management, 355, 47-49. (In Chinese)

Feng, L., Tang, S., \& Ma, R. (2017). Research on Optimizing the Path of Health Poverty Alleviation Based on Supply-Side Reform. Health Economics Research, 4, 19-22. (In Chinese)

Gao, H., Chen, H., Feng, J., Qin, X., Wang, X., Liang, S., Zhao, J., \& Feng, Q. (2018). Balanced Scorecard-Based Performance Evaluation of Chinese County Hospitals in Underdeveloped Areas. Journal of International Medical Research, 46, 1947-1962. https://doi.org/10.1177/0300060518757606

Gardner, K., Sibthorpe, B., Chan, M., Sargent, G., Dowden, M., \& McAullay, D. (2018). Implementation of Continuous Quality Improvement in Aboriginal and Torres Strait Islander Primary Health Care in Australia: A Scoping Systematic Review. BMC Health Services Research, 18, 541. https://doi.org/10.1186/s12913-018-3308-2

George, A. S., Campbell, J., \& Ghaffar, A. (2018). Advancing the Science behind Human Resources for Health: Highlights from the Health Policy and Systems Research Reader on Human Resources for Health. Health Research Policy and Systems, 16, 80. https://doi.org/10.1186/s12961-018-0346-5

Glen, P. M., \& Cezar, B. M. (2017). Public Health Spending and Medicare Resource Use: A Longitudinal Analysis of U.S. Communities. Health Services Research, 2, 2357-2377. https://doi.org/10.1111/1475-6773.12785

Gong, X., \& Hu, S. (2005). Analysis of Equity in the Distribution of Health Care Resources. Chinese Journal of Hospital Administration, 2, 73-77. (In Chinese)

Gupta, H. (2018). Assessing Organizations Performance on the Basis of GHRM Practices Using BWM and Fuzzy TOPSIS. Journal of Environmental Management, 15, 201-216. https://doi.org/10.1016/j.jenvman.2018.08.005

Hosseini, M., Bahadori, M., Raadabadi, M., \& Ravangard, R. (2019). Ranking Hospitals Based on the Disasters Preparedness Using the TOPSIS Technique in Western Iran. Hospital Topics, 97, 1-9. https://doi.org/10.1080/00185868.2018.1556571

Konings, P., Harper, S., Lynch, J., Hosseinpoor, A. R., Berkvens, D., Lorant, V., Geckova, A., \& Speybroeck, N. (2010). Analysis of Socioeconomic Health Inequalities Using the Concentration Index. International Journal of Public Health, 55, 71-74. https://doi.org/10.1007/s00038-009-0078-y

Li, B., Liu, Z., Li, Y., Chun, L., Xu, J., \& Li, M. (2019). Classification of Regional Health Resources in Hubei Province. Chinese Health Resources, 22, 106-110. (In Chinese)

Li, J., Shi, L., Liang, H., Ding, G., \& Xu, L. (2018). Urban-Rural Disparities in Health Care Utilization among Chinese Adults from 1993 to 2011. BMC Health Services Research, 18, 102. https://doi.org/10.1186/s12913-018-2905-4

Li, W. (2016). An Empirical Study of Economic Growth in Chongqing's Urban Counties. Ph.D. Thesis, Chongqing: Chongqing University.

Liang, X. (2003). The Impact of the Current Financial Investment Mechanism on Disease Control. The Chinese Health Service Management, 4, 243-244. (In Chinese)

Ma, T., Li, J., Zhang, L., Zhang, R., \& Zhang, Q. (2019). Evaluation of Primary Medical 
and Health Service Quality in a Community of Changchun City Based on TOPSIS and RSR Methods. Medicine and Society, 32, 49-52. (In Chinese)

Ouyang, H., \& Zhang, Z. (2016). Analysis on the Equalization of Provincial Health Resources Allocation in China. Chinese Health Economics, 35, 36-38. (In Chinese)

Pang, Q., Wang, X., Luo, H., Jian, N., You, J., \& Feng, Q. (2015). Using Neural Network Model to Evaluate the Index of the Operation Efficiency of the Public Medical and Health Institutions at County Level. The Chinese Health Service Management, 32, 911-915. (In Chinese)

Peng, R., Liu, H., \& Zhang, M. (2019). Study on Regional Differences in Social Care Service Input Level by Using Entropy Weight TOPSIS Method. Chinese Journal of Health Policy, 12, 42-47. (In Chinese)

Shen, X., Gan, E., \& Xu, Y. (2019). Evaluation of Health Resource Allocation in Western China Based on Agglomeration Degree. Medicine and Society, 7, 32-35. (In Chinese)

Shi, W., \& Tang, D. (2015). Path Choices and Innovations to Solve the Plight of Elderly Care Services in Underdeveloped Areas. China Public Administration, 4, 94-98. (In Chinese)

Song, X., Wei, Y., Deng, W., Zhang, S., Zhou, P., Liu, Y., \& Wan, J. (2019). Spatio-Temporal Distribution, Spillover Effects and Influences of China's Two Levels of Public Healthcare Resources. International Journal of Environmental Research and Public Health, 16, 582. https://doi.org/10.3390/ijerph16040582

Sun, J., \& Luo, H. (2017). Evaluation on Equality and Efficiency of Health Resources Allocation and Health Services Utilization in China. International Journal for Equity in Health, 16, 127. https://doi.org/10.1186/s12939-017-0614-y

Tao, Y., Henry, K., Zou, Q., \& Zhao, X. (2014). Methods for Measuring Horizontal Equity in Health Resource Allocation: A Comparative Study. Health Economics Review, 4, 10. https://doi.org/10.1186/s13561-014-0010-x

Tursunbayeva, A., Pagliari, C., Bunduchi, R., \& Franco, M. (2015). Human Resource Information Systems in Health Care: Protocol for a Systematic Review. JMIR Research Protocols, 4, 135. https://doi.org/10.2196/resprot.4922

Wang, Y., Tu, Q., Lai, Q., \& Huang, L. (2015). Fairness or Not? Health Resources Allocation in Chongqing : Based on Theil Index. Open Journal of Social Sciences, 3, 117-123. https://doi.org/10.4236/jss.2015.37020

Wei, X., Liu, X., Cheng, L., Sun, L., Pan, Y., \& Zong, W. (2017). Evaluating Medical Convenience in Ethnic Minority Areas of Southwest China via Road Network Vulnerability: A Case Study for Dehong Autonomous Prefecture. International Journal for Equity in Health, 16, 206. https://doi.org/10.1186/s12939-017-0702-Z

$\mathrm{Xu}, \mathrm{C}$. (2011). The Fundamental Institutions of China's Reform and Development. Journal of Economic Literature, 10, 1076-151. https://doi.org/10.1257/jel.49.4.1076

Xu, K., Zhang, K., Wang, D., \& Zhou, L. (2014). Trend in Distribution of Primary Health Care Professionals in Jiangsu Province of Eastern China. International Journal for Equity in Health, 13, 117. https://doi.org/10.1186/s12939-014-0117-z

Zhang, J., Tang, G., \& He, Z. (2020). The Main Achievements and Basic Experience of China's Medical and Health Undertakings in the New Period. Journal of Liaoning Academy of Governance, 1, 40-44. (In Chinese)

Zhang, T., Meng, Z., Ma, Z., Chen, L., Li, Z., Cai, Y., \& Wu, H. (2019). Economic Status of County-Level Disease Control and Prevention Institutions in Underdeveloped Areas of China and Its Influence on their Operation. Chinese Health Resources, 22, 274-278. (In Chinese) 
Zhang, Y., Wang, Q., Jiang, T., \& Wang, J. (2018). Equity and Efficiency of Primary Health Care Resource Allocation in Mainland China. International Journal for Equity in Health, 17, 140. https://doi.org/10.1186/s12939-018-0851-8

Zhou, Q., \& Ni, J. (2017). Perspective on the Equity of Health Human Resources Allocation in Sichuan Province. Soft Science of Health, 2, 18-22. (In Chinese) 


\section{Appendices}

In order to promote the further optimization of health resources allocation in China, improve service accessibility, capacity and resource utilization efficiency, and guide local governments to scientifically and rationally formulate regional health plans and medical institution setting plans, the State Council of the PRC. formulated the Outline of the National Medical Service System Planning 2015-2020. The outline focused on building an integrated health service system that was compatible with the level of national economic and social development and that meets the health needs of residents. It regulates the allocation of health resource elements in the national medical and health service system. Its main indicators were as follows.

Major indicators of resources allocation in china's healthcare service system in 2020.

\begin{tabular}{|c|c|c|}
\hline Main Indicators & 2020 Targets & 2013 Status \\
\hline $\begin{array}{l}\text { Number of beds in medical and health institutions } \\
\text { per } 1000 \text { resident population }\end{array}$ & 6 & 4.55 \\
\hline Hospitals & 4.8 & 3.56 \\
\hline Public hospitals ${ }^{*}$ & 3.3 & 3.04 \\
\hline Provincial and above hospitals & 0.45 & 0.39 \\
\hline Municipal hospitals & 0.9 & 0.79 \\
\hline County hospitals & 1.8 & 1.26 \\
\hline Other public hospitals & 0.15 & 0.60 \\
\hline Private hospitals & 1.5 & 0.52 \\
\hline Primary health care institutions & 1.2 & 0.99 \\
\hline $\begin{array}{l}\text { Number of practicing (assistant) physicians } \\
\text { per } 1000 \text { resident population }\end{array}$ & 2.5 & 2.06 \\
\hline Registered nurses per 1000 resident population & 3.14 & 2.05 \\
\hline Public health personnel per 1000 resident population & 0.83 & 0.61 \\
\hline General practitioners per 10,000 resident population & 2 & 1.07 \\
\hline Ratio doctors to nurses & $1: 1.25$ & $1: 1$ \\
\hline Ratio of beds to nurses in municipal hospitals and above & 1:0.6 & $1: 0.45$ \\
\hline Number of suitable beds in county general hospitals & 500 & - \\
\hline Number of suitable beds in county municipal hospitals & 800 & - \\
\hline Number of suitable beds in provincial and above hospitals & 1000 & - \\
\hline
\end{tabular}

*. Provincial hospitals are operated by provinces, autonomous regions, or municipalities. Municipal hospitals are operated by prefecture-level cities, regions, states, or leagues; County hospitals are operated by counties, county-level cities, municipal districts, or flags. 